\title{
Qhapaq Ñan, Sistema Vial Andino: el desafío de su conservación en Chile en el marco de su nominación a la Lista del Patrimonio Mundial
}

\author{
Solange Díaz Valdés
}

\begin{abstract}
El concepto Qhapaq Ñan, como bien para ser inscrito en la Lista del Patrimonio Mundial es fundamentalmente una voluntad, un propósito político, concebido a partir de una herencia material

parcialmente conservada, pero no completamente conocida y que aún no está registrada ni inventariada.
\end{abstract}

Ciro Caraballo Perichi, 2004

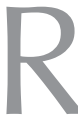
eflexionar sobre la definición, la gestión y la conservación del Qhapaq Nan (en quechua, Camino Principal, o Camino del Señor) es una tarea compleja que va aparejada con la trayectoria del proceso de su nominación a la Lista del Patrimonio Mundial de la Organización de la Naciones Unidas para la Educación, la Ciencia y la Cultura (UNESCO). Ciertamente gracias al firme propósito político de seis países: Perú, Chile, Ecuador, Argentina, Colombia y Bolivia, y con el apoyo del Comité de Patrimonio Mundial (WHC, por sus siglas en inglés), se ha logrado definir y priorizar los elementos más significativos de uno de los bienes culturales de mayor sofisticación en el mundo, con el fin de rearticular una red multinacional conformada por nuevas investigaciones, proyectos, acuerdos y la participación comunitaria que se enlaza en una escala regional. Efectivamente, se trata de una apuesta que no sólo busca destacar el valor arqueológico de una de las obras precolombinas sudamericanas de gran extensión y variabilidad en sus componentes, sino también aproximarnos a la significación y vigencia de la cosmovisión andina. Así, este INFORME tiene como finalidad tanto explicar la relevancia multivocal del Qhapaq Ñan como analizar los esfuerzos que desde el Consejo de Monumentos Nacionales (CMN), organización del gobierno de Chile, se han realizado para la protección, preservación, difusión y reactivación de una obra patrimonial única de la humanidad. 


\section{¿Qué es el Qhapaq Ñan?}

El Sistema Vial Andino, hoy denominado Qhapaq Ñan, es una extensa red de caminos, de más de $30000 \mathrm{~km}$ de longitud, que se consolidó a lo largo y ancho de la Cordillera de los Andes durante la época de ocupación del imperio incaico en un periodo de poco menos de 100 años, aproximadamente entre 1438 y 1533 (Figura 1).

Para comprender su complejidad material e inmaterial se requiere, por lo tanto, detallar históricamente su constitución. Como es sabido, el Tawantinsuyu o imperio incaico, que abarcó los territorios de las actuales naciones de Argentina, Bolivia, Colombia, Chile, Ecuador y Perú, tuvo su capital en la ciudad de Cuzco (hoy Perú). Fue precisamente ahí, en la urbe cuzqueña, donde se ubicaba (y actualmente persiste) una plaza central desde la cual nacían los cuatro caminos principales que permitían recorrer los rincones del territorio conquistado: el Chinchaysuyo (Chinchay Suyu) al norte, el Collasuyo (Qulla Suyu) al sur, el Antisuyo (Anti Suyu) al este y el Contisuyo (Kunti Suyu) al oeste, a partir de los cuales se conformaron varios ramales de tránsito. Asociados a esta red de caminos se construyeron asentamientos e instalaciones de distinta envergadura y jerarquía, cuya instauración dependió tanto de las intenciones y decisiones político-administrativas que el Inca tenía sobre los territorios anexados como de las condiciones geológicas, ambientales y sociales que imperaban en el entorno natural.

No obstante, el Qhapaq Ñan no puede considerarse como una obra de exclusiva adscripción cultural incaica: se trata, efectivamente, de un sistema vial que en gran medida integró el conocimiento que sobre el medio geográfico ya existía entre previos pueblos andinos, quienes definieron gran parte del trazado, el cual posteriormente sirvió de cimiento para que la obra del pueblo Inca formalizara una de las infraestructuras viales más complejas e íntegras del mundo, expresión de un logro extraordinario de comunicación y conectividad en un medio ambiente dramático, difícil y heterogéneo (ENQÑ 2013).

Como tal, el Qhapaq Ñan es un ejemplo cultural destacado de la conjunción del esfuerzo de los seres humanos en su interacción con la naturaleza. Su riqueza como vía de comunicación e intercambio adquiere mayor relevancia al considerar la diversidad y singularidad de las distintas sociedades que habitaron las diferentes regiones donde se asentó el camino. Así, a lo largo de la historia, el trazado del Qhapaq Nan ha servido como materia y medio de expresión de las culturas andinas pasadas y vivas que, mediante edificación y uso, han transmitido su capacidad de convertir una de las geografías más hostiles del continente americano en "ambiente de vida" (cfr. Caraballo y Saez 2004) (Figura 2). Asimismo, el Sistema Vial Andino representa una forma de interacción e intercambio intercultural, donde la civilización y la tradición andinas se han activado y resignificado durante cientos de años. Hoy en día sigue en uso y su futuro es materia de

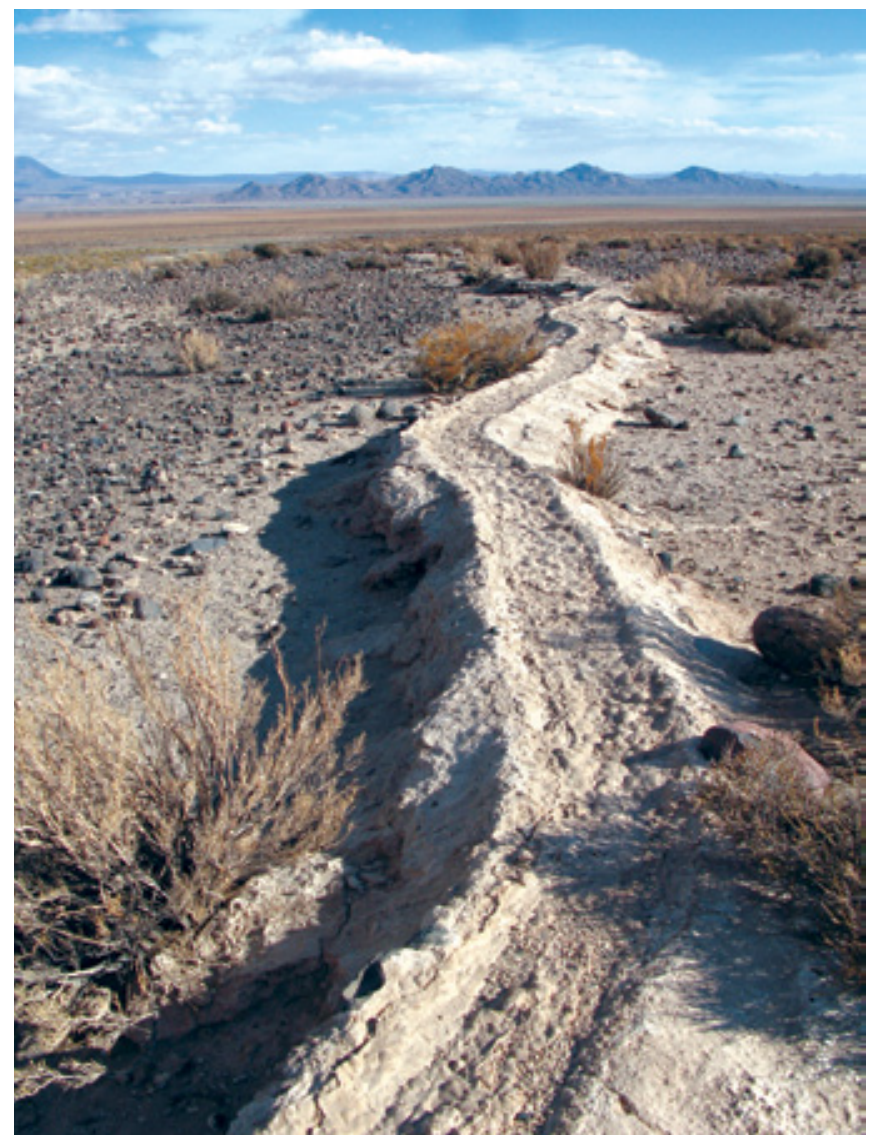

FIGURA 1. Canales arqueológicos en las cercanías del Subtramo CupoCatarpe, Qhapaq Ñan, Chile (Cortesía: CMN, Chile, 2010).

interés de las distintas comunidades, que le confieren diversos significados y potencialidades. Esta red vial es, así, un patrimonio vivo.

\section{El proceso de nominación multinacional de un itinerario cultural}

Reconocido el Qhapaq Ñan como un patrimonio común a diversas naciones, fue a mediados del año 2001 cuando el gobierno del Perú empezó a promover ante la UNESCO la Postulación Multilateral del "Camino del Inca" ${ }^{1}$ como Sitio del Patrimonio Mundial en la categoría de itinerario cultural. Para tal efecto, la iniciativa, que buscaría la nominación del bien a través de una selección de sus tramos e hitos más notables, se propuso a los gobiernos de los países andinos cuyos territorios hubiesen estado ocupados por el Tawantinsuyu.

Una vez que las comunicaciones sobre la propuesta se establecieron y formalizaron por vías diplomáticas hacia las representaciones de cada uno de los Estados, fue en la XVII Cumbre del Grupo de Río (2003), realizada en Cuzco, cuando los mandatarios de Chile, Bolivia, Argentina, Colombia, Perú y Ecuador reafirmaron su voluntad de prosperar en aquélla, afirmando que "el Qhapaq Ñan

\footnotetext{
${ }^{1}$ Denominado así en ese momento.
} 


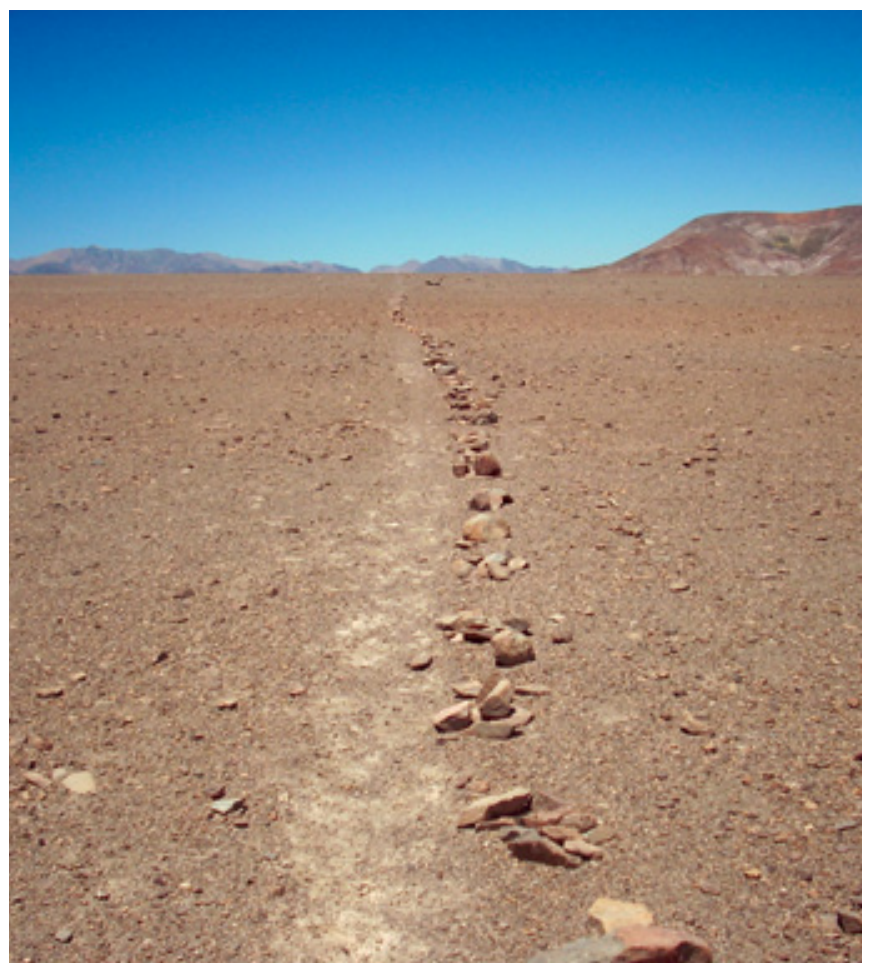

FIGURA 2. La fragilidad del camino en el Desierto de Atacama, Subtramo Portal del Inca-Finca Chañaral, Sistema Vial Andino, Chile (Cortesía: CMN, Chile, 2011).

representa uno de los símbolos de su antigua integración". Con ello se conformó una dinámica de colaboración multinacional que de manera concertada buscaba cumplir con el desafío planteado. Así, con el apoyo de la UNESCO y de otras entidades latinoamericanas, se emprendió una coordinación internacional con el fin de avanzar en la constitución del expediente de nominación requerido. Como lo señala el consultor internacional en materia patrimonial Ciro Caraballo Perichi el proceso de postular el Qhapaq Ñan a la lista se inició "con una férrea voluntad y propósito político" (cfr. Caraballo y Sanz 2004), condición que ha prevalecido durante los casi 13 años de trabajo de conformación del expediente.

Dados estos orígenes, y por razones obvias, la propia nominación transfronteriza ha tenido dos vías paralelas de desarrollo en sus acuerdos, tareas y avances: los políticos y los técnicos. Si bien la intensidad de gestión en cada uno de estos ámbitos ha cambiado conforme a las necesidades propias de la iniciativa y en la medida en que se han establecido compromisos políticos para su finalización, el proceso también se ha convertido en una experiencia inédita de investigación, cooperación e intercambio interdisciplinario regional, cuyos resultados trascienden la meta de conformar un expediente de nominación a la Lista del Patrimonio Mundial: a la par del ahondamiento en la historia y actualidad del Qhapaq $\tilde{N} a n$, se ha proyectado la puesta en valor de sus recursos culturales, incluidos aquellos de naturaleza arqueológica y otros de tipo natural, social y asociativo, la cual pretende la conservación del "ambiente de vida" y de relaciones culturales únicas del mundo andino.

Un aspecto digno de mencionar es que la definición de los objetos del proceso de nominación del Qhapaq Nan concibe que su conservación ha de lograrse con la participación de las comunidades asociadas, con lo que se promueve su adecuado desarrollo social y económico, a la vez que, por medio de la incorporación de lo que sus individuos denominan buen vivir, o suma qamaña, ${ }^{2}$ reconoce la cosmovisión andina del camino a través de las prácticas y formas de articular la conceptuación de dicho desarrollo. Esta visión integrada ha implicado la realización de programas y proyectos de investigación, promoción y conservación que han derivado en avances sustanciales tanto en el plano científico como en la protección y puesta en valor de los bienes culturales, todo ello con base en una cimentación tendente al desarroIlo sostenible del patrimonio, y al respeto a la identidad andina en su diversidad pluriétnica y multicultural. Dicho de otro modo, estos fundamentos precisaron una serie de principios rectores, entre los que destaca el de la postulación como una iniciativa de carácter multilateral e integradora de los países participantes, cuyas estrategias, con un enfoque multidisciplinario e interinstitucional, pondrían especial énfasis en un desarrollo social y económico de las comunidades tal que derivaría en una concepción integrada del patrimonio, donde se conjugarían lo cultural y lo natural, lo tangible y lo intangible, la herencia del pasado y la realidad contemporánea. Asimismo, se estableció que las acciones que se llevaran a cabo respetarían la identidad cultural de las comunidades y pueblos indígenas ligados al Qhapaq Ñan (Figura 3).

\section{El desarrollo del proceso de nominación}

El desarrollo del proceso de nominación, con especial referencia al caso chileno, puede resumirse en las siguientes fases:

2001-2003: instauración política e institucional de la iniciativa en cada país.

2004-2005: aproximación científica, creación de Comité Científico y construcción de la fórmula para la nominación.

2006-2008: coordinación técnica y homologación de criterios técnicos para el registro en arqueología, medio ambiente, oralidad, etnografía, geología, cartografía e historia, y creación del Comité Jurídico.

2009-2013: Conformación de secretarías técnicas nacionales, avances en aspectos de gestión y conservación, formulación del expediente de nominación y su entrega al WHC.

\footnotetext{
${ }^{2}$ En idioma quechua.
} 


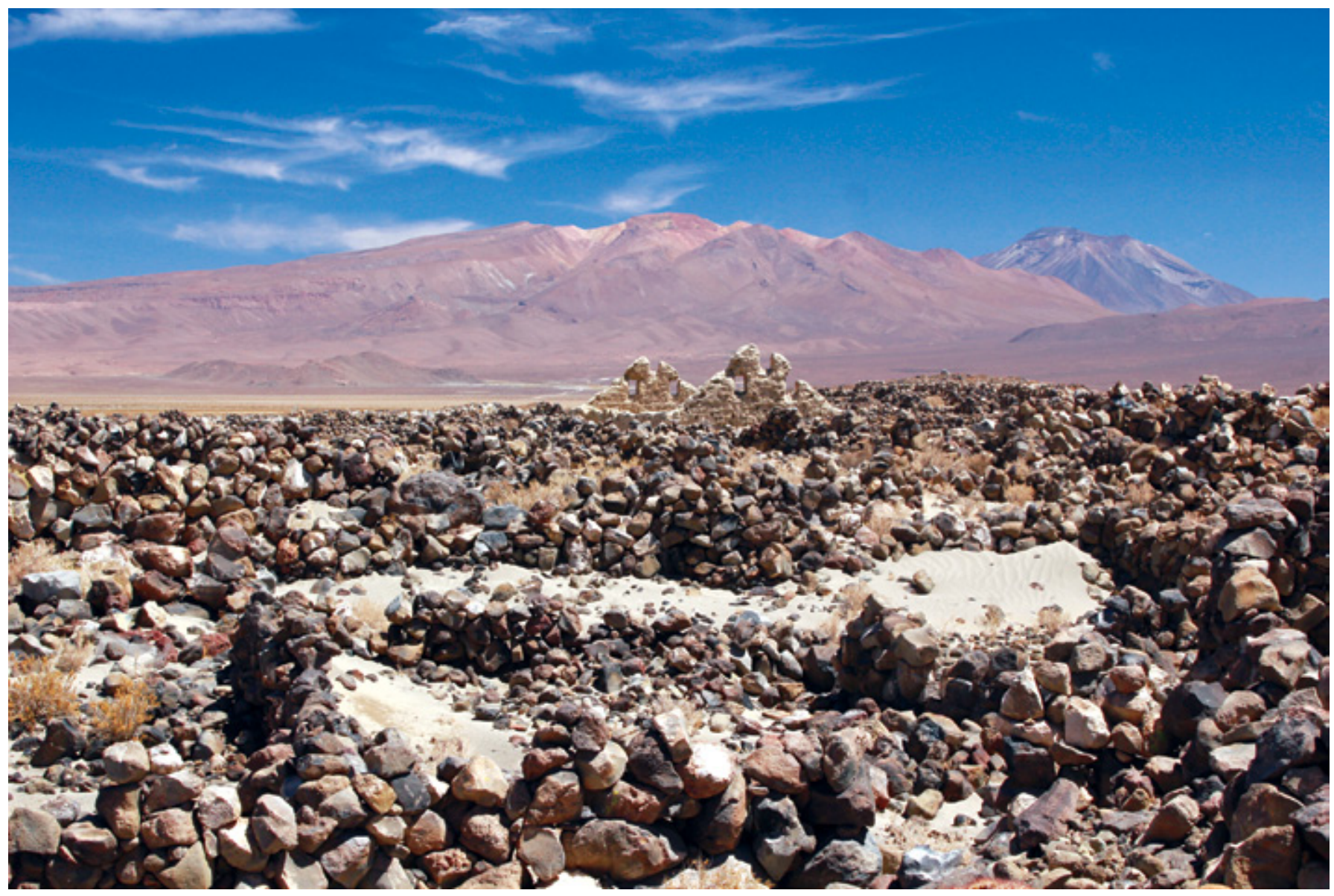

FIGURA 3. Sitio arqueológico de Turi asociado al Qhapaq Ñan, Chile (Cortesía: CmN, Chile, 2011).

En la primera etapa (2001-2003) se consolidó el compromiso político y se convino el punto de partida común: un momento caracterizado por las acciones que sirvieron para poner el bien cultural en la palestra y definir aquellas que habían de emprenderse en fases subsecuentes, que apuntarían, tanto desde el orden administrativo como del técnico, a su salvaguardia. Un logro fundamental de este periodo es el liderazgo de las cancillerías de cada uno de los países, que son las que encabezan las definiciones y toman los acuerdos de carácter internacional.

En una segunda etapa (2004-2005) se traspasaron las responsabilidades a los organismos técnicos encargados en cada país, con lo que se propiciaron, con base en reuniones con expertos académicos del mundo andino, las primeras discusiones conceptuales sobre el bien cultural. Aquí vale la pena subrayar que uno de los primeros acuerdos internacionales fue el reconocimiento de la temporalidad de los caminos que conforman la red, del que se estableció que un gran número de ellos son precedentes a la llegada de los incas a los territorios anexados, concepción que derivó en la resolución de nombrar al sistema vial, en lugar de Camino del Inca, Qhapaq Nan, denominación que reconoció el logro compartido de los pueblos andinos en conjunto con el Inca para la consolidación de aquél. Asimismo, para favorecer una mejor comprensión del término quechua, se agregaron los conceptos de red y camino, presentes en la noción sistema vial andino.

En una tercera etapa (2006-2008) se fortalecieron los equipos técnicos nacionales, que fijaron dos tipos de criterio para la selección de los segmentos: unos de carácter internacional y otros de aplicación nacional. Los primeros estarían enfocados en seleccionar aquellos segmentos que contaran con valor(es) universal(es) excepcional(es), cumpliendo con ello algunos de los criterios culturales, así como con las condiciones de integridad/autenticidad a que obligan los requerimientos establecidos en las Directrices Operativas de la Convención de Patrimonio Mundial, Cultural y Natural (UNESCO 2013) para la integración de sitios en la Lista del Patrimonio Mundial. Para la determinación del segundo conjunto de criterios, cada país adoptó una serie de pautas complementarias vinculadas con las distintas realidades locales, de territorio y de marco institucional, incluidos la representatividad territorial, contextual y tecnológica, los tipos de instalaciones vinculadas, la función y jerarquía en la red, la factibilidad de gestión y, con la mira puesta en el desarrollo sostenible, la viabilidad del empoderamiento local. 


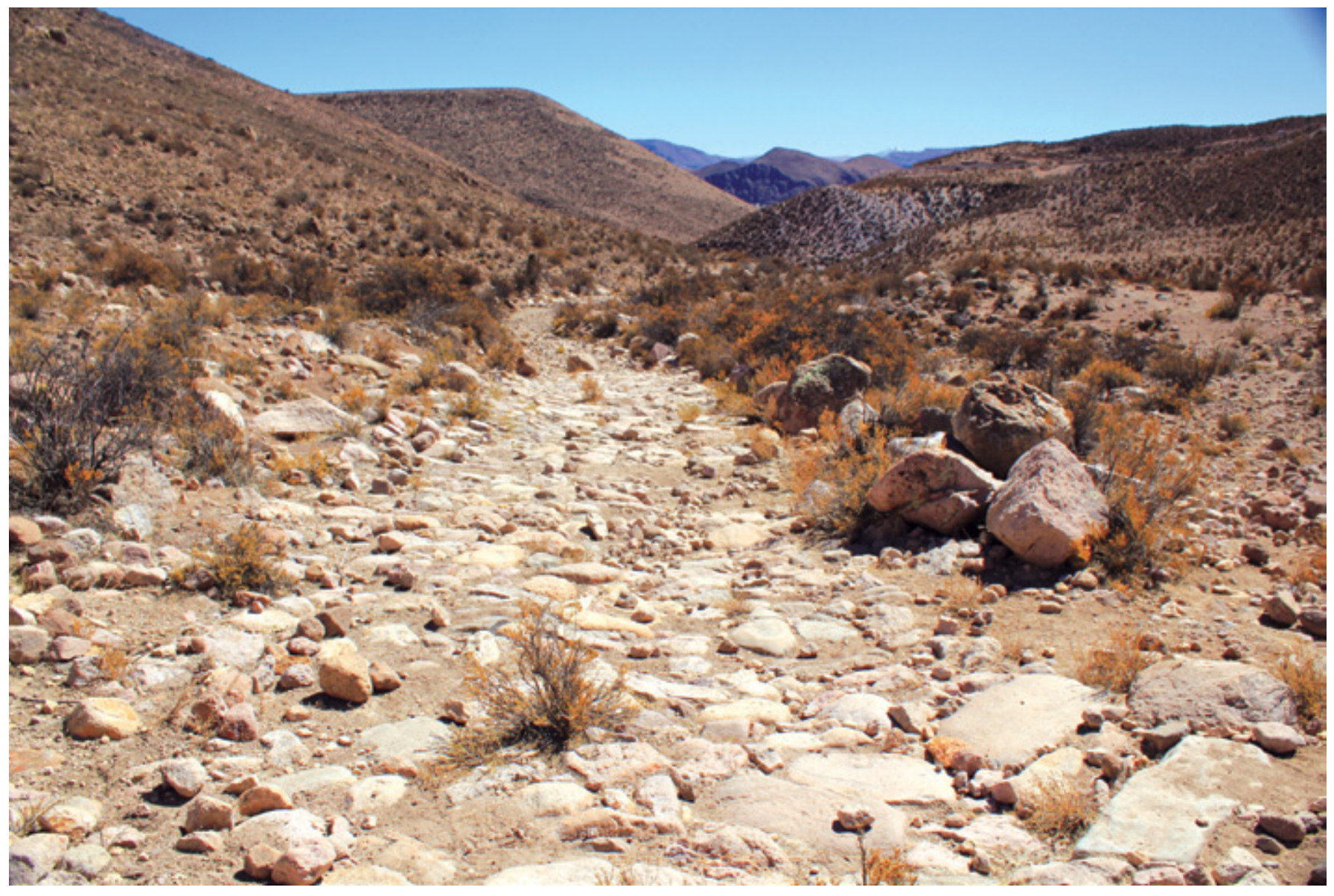

FIGURA 4. Subtramo Putre-Zapahuira, Qhapaq Nan, Chile (Cortesía: CMN, Chile, 2010).

En la cuarta etapa (2009-2013) se consolidaron las estructuras nacionales e internacionales con vistas a la gestión del bien. Para ello se realizaron varias reuniones, cuyo objeto consistió en orientar la administración y la conservación del bien, en las que se establecieron preceptos y posturas comunes. En el ámbito nacional se fueron ajustando las selecciones de segmentos de acuerdo con las pautas acordadas. Finalmente, se estipularon los pasos que habían de seguirse para la construcción del expediente único de nominación. Se seleccionaron 720.79 km entre los miles de vialidad y 291 sitios arqueológicos asociados al Qhapaq Ñan, que se han nominado este año (2013) a la Lista del Patrimonio Mundial de la UNESCO en la categoría de itinerario cultural de naturaleza transnacional, mediante un expediente que comprende un cabal estudio tipológico de caminos y sitios arqueológicos que lo configuran como tal. Todos estos elementos contienen la variedad existente en los seis países.

Durante las investigaciones multidisciplinarias se identificaron abundantes variantes tipológicas de camino y de sitios arqueológicos asociados, según la función que éstos prestaban al Tawantinsuyu. Específicamente, a partir del registro arqueológico se establecieron 61 tipos de sitios asociados, y 8 tipos de camino con 56 variantes, ${ }^{3}$ los que, sin ser exclusivos de un país, pueden aparecer en los territorios de varios de ellos. Asimismo, los tipos de camino se han definido dependiendo de su morfología: Despejado, Plataforma (Corte talud), Empedrado, Encerrado por muros, Excavado y/o Tallado en roca, Con escalinatas, Calzada elevada, Corte y relleno. Respecto de los sitios, se organizaron, de acuerdo con la

\footnotetext{
3 Técnicas constructivas del camino: Sin aparejo, Aparejo ensamblado, Aparejo celular almohadillado, Aparejo rectangular, Almohadillado, Aparejo ciclópeo, Tallado en roca, Tierra-piedra-mixto, Por sustracción, Desgaste por uso continuo, Despeje de rocas superficiales, Raspado, Por adición, Por acomodo de sustrato existente. Tipos de sitios: Recintos, Canchas, Tambo, Huayrana, Ushno, Chaskiwasi, Plataformas artificiales, Murallas, Muros, Cementerios, Huacas, Apachetas, Petroglifos, Andenes, Pintura rupestre, Huacas naturales, Rocas esculpidas, Canteras, Montículos artificiales, Cuevas/abrigos, Basurales, Acueductos, Reservorios, Canales, Encauzamientos de ríos, Chullpas, Cistas, Tumbas en risco o farallón, Plaza o canchas, Plaza hundida, Pirámide trunca, Estructuras en U, Depresiones artificiales, Qochas/camellones, Monolitos/estelas, Escalinatas, Rampas, Fuentes de agua, Qolqas, Minas, Puente, Complejo arquitectónico, Centro administrativo, Recintos o estructuras aisladas, Pukaras, Corral, Conchal, Cantera taller lítico, Tumba aislada, Tumba de cista o bóveda, Santuario de altura, Piedra tacita, Rocas esculpidas, Geoglifos, Campamento minero, Estructura de acopio o depósitos y otros.
} 


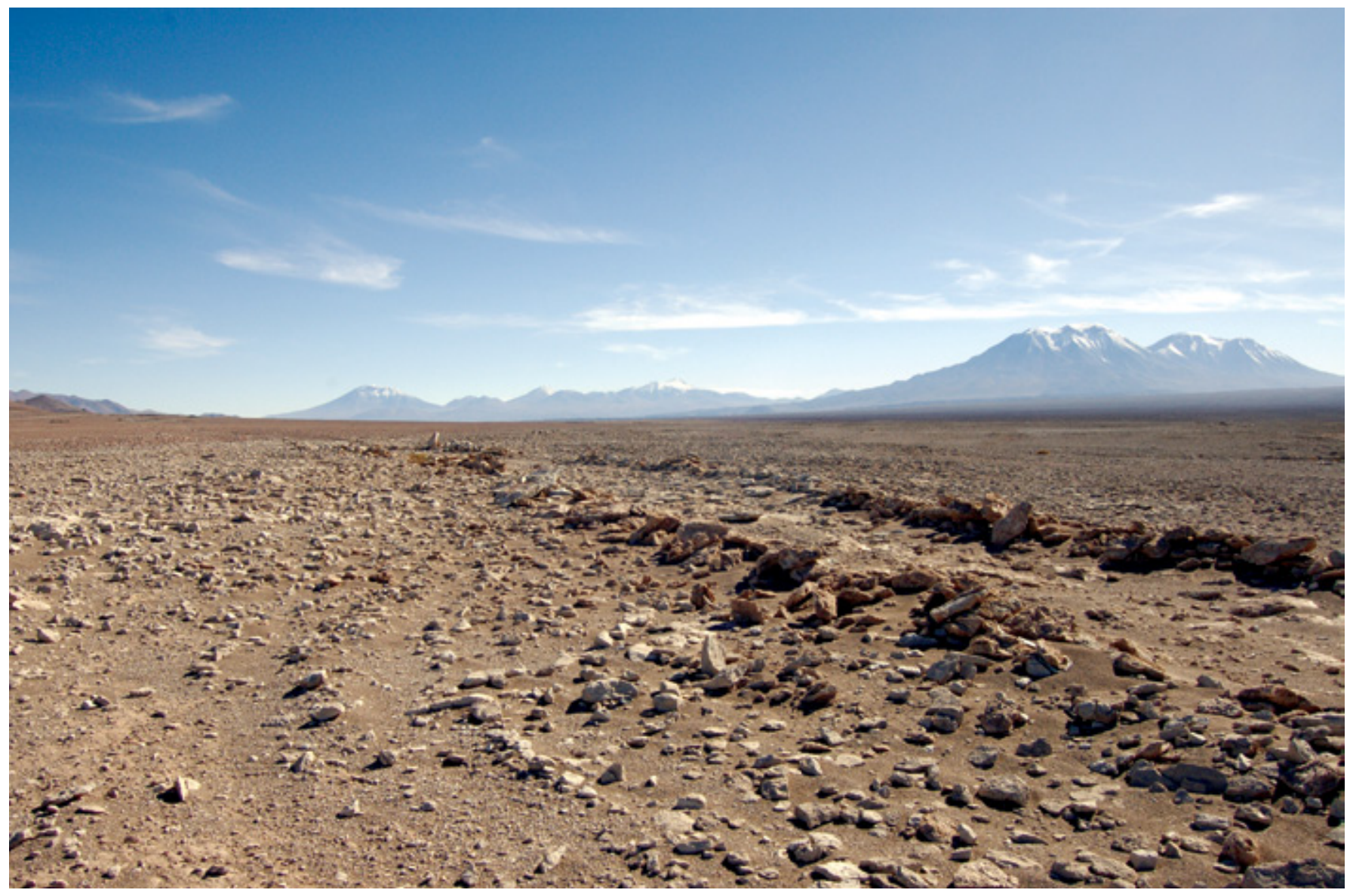

FIGURA 5. Subtramo Incahuasi-Lasana, Sistema Vial Andino, Chile (Cortesía: CMn, Chile, 2011).

función que cumplían, en tres grandes grupos de arquitectura: 1) asociada al camino, 2) religiosa y de poder, y 3) doméstica. ${ }^{4}$

En la justificación de sus valores para la inscripción del Qhapaq Ñan en la Lista del Patrimonio Mundial -expresa en el expediente de su nominación (cfr. EXPN 2013)_se ha fundamentado que este itinerario cultural cumple con los seis criterios de valor cultural excepcional, por cuanto: 1) representa una obra maestra del genio creador humano; 2) atestigua un intercambio de valores humanos considerable; 3) aporta un testimonio único, o al menos excepcional, sobre una tradición cultural de una civilización; 4) es una muestra eminentemente representativa de tipo de construcción, conjunto arquitectónico o tecnológico y de paisaje, que ilustra un periodo significativo de la

\footnotetext{
${ }^{4}$ Se presentan ocho tipos de arquitectura asociada al camino: Puentes, Andenes, Qolqas, Graneros, Canales, Estructuras de señalización, Pinturas rupestres y Petroglifos, a partir de los cuales se desarrollan diecinueve variantes. Por un lado, nueve tipos de estructuras se asocian a la arquitectura religiosa y de poder: Kallankas, Palacios, Templos, Usnu, Pukará, Tambos, Estructuras ortogonales, Chullpas y Centro ceremonial, a partir de las cuales se desarrollan 21 variantes. Por otro, lado se presentan cuatro variedades de estructuras de arquitectura doméstica: Kancha, Masma, Vivienda y Bohío.
}

historia humana; 5) es un ejemplo destacado de una forma tradicional de asentamiento humano y de utilización del territorio, representativa de una cultura, y 6) está directamente asociado con tradiciones vivas, ideas y creencias que tienen una importancia universal excepcional.

Vale la pena señalar que, una vez culminadas las fases de diagnóstico y con avances considerables en el proceso de desarrollo estratégico de planificación, este año, 2013, ya se ha hecho entrega del expediente de nominación a las autoridades competentes.

\section{El Qhapaq Ñan en Chile: componentes}

En el sector norte de Chile los incas consolidaron e instituyeron dos rutas longitudinales: la primera, por las tierras altas de la vertiente occidental andina, uniendo altiplanos y salares, y la segunda, que atraviesa por tierras más bajas, empezando en la costa de Arica e internándose en el valle central, hasta ingresar en las nacientes del río Loa. En el Desierto de Atacama, el Inca se encontró con el mayor desafío ambiental para su empresa de infraestructura vial, lo que da cuenta de la férrea voluntad y necesidad de expansión imperial en estas tierras, al parecer motivada principalmente por el deseo de obtener recursos minerales. 
Para la nominación, en Chile se seleccionaron cinco segmentos ubicados en el norte del país, los cuales se denominaron: subtramos Putre-Zapahuira, Incahuasi-Lasana, Cupo-Catarpe, Camar-Peine, y Portal del Inca-Finca Chañaral ${ }^{5}$ (Figura 4). Esta selección suma 112 km y 138 sitios arqueológicos, ${ }^{6}$ lo que comprende una zona núcleo de 136 ha y una de amortiguamiento de 6407 hectáreas.

Estos segmentos de camino seleccionados están asociados a un total de diez comunidades, ocho de las cuales son de población indígena aymara y atacameña; el carácter de las dos restantes es urbano-rural, con marcada población pirquinera, dedicada a la pequeña minería.

Tipológicamente, los caminos seleccionados en territorio chileno están condicionados por la travesía por el desierto más árido del mundo, lo que determina que la mayor parte de los segmentos se definan como del tipo "despejado"; 7 sólo los casos de los que se ubican en el extremo norte (Subtramo Putre-Zapahuira) (Figura 5) presentan condiciones geomorfológicas cordilleranas, que los hacen sinuosos y de mayor riqueza en cuanto a las soluciones tecnológicas ideadas para su construcción. Si bien la tecnología constructiva del Qhapaq Ñan en la parte correspondiente a Chile aparentemente no tiende a presentar un carácter monumental, resulta impactante la linealidad de su trazado, lo que evidencia la enorme capacidad de quienes lo diseñaron para asimilar el espacio geográfico en que habitaron y desarrollaron sus travesías (Infracon 2012).

Es importante señalar que el proceso para seleccionar los tramos que entrarían en el expediente de nominación del Qhapaq Ñan en Chile no fue fácil ni estuvo carente de conflictos y discordias, tanto por la mirada crítica que la academia ha hecho del proyecto como, desde luego, por la desconfianza o indiferencia de las comunidades locales ante una iniciativa que, en primera instancia, entendían foránea a sus costumbres. Así, de cara a la academia, ${ }^{8}$ se establecieron mecanismos de comunicación que promovieran una diferenciación sobre la naturaleza del Qhapaq Ñan en relación con la iniciativa de nominación, que apunta a su carácter eminentemente cultural, y el trazado del camino como evidencia arqueológica, una divergencia de forma mas no de contenido, ya que el legado patrimonial puede concebirse como

\footnotetext{
${ }^{5}$ Se acordó internacionalmente que los segmentos se denominarían de la siguiente manera: tramo, aquel con continuidad superior a $100 \mathrm{~km}$; subtramo, con continuidad menor a $100 \mathrm{~km}$ y superior a $10 \mathrm{~km}$, y sección, segmento con continuidad hasta de 10 kilómetros (cfr. EXPN 2013). ${ }^{6}$ En su mayoría, sitios de mediana y pequeña magnitud.

${ }^{7}$ El camino despejado se formaliza debido al desgaste por uso continuo. ${ }^{8}$ Lo importante aquí no es reseñar la situación de la arqueología en Chile, tema que corresponde a otra publicación, sino señalar que no se hace arqueología desde el Estado debido a la precariedad legal e institucional que se explica en el siguiente apartado; por lo tanto, el gremio tiene el control de las investigaciones, de las publicaciones y del quehacer profesional en general.
}

común. Así, se apostó por una reconfiguración del campo de acción de la arqueología y otras disciplinas afines respecto de sus objetivos últimos, en la que se privilegió la protección del bien patrimonial. Ello, por lo tanto, se alineó con los preceptos de la Carta Internacional para la Gestión del Patrimonio Arqueológico que establece:

La protección de este patrimonio no puede basarse únicamente en la aplicación de técnicas arqueológicas. Exige un fundamento más amplio de competencias y conocimientos profesionales y científicos (cfr. ICOMOS 1990).

Finalmente, y después de diferentes encuentros y reuniones, se logró que los investigadores más connotados en materia incaica se sumaran al proyecto nacional.

Respecto de la relación con las comunidades, fue fundamental que se dispusiera de una línea de trabajo, inédita tanto en el ámbito institucional como en lo que concierne al quehacer del Estado, con la finalidad de establecer mecanismos para la construcción de confianzas entre las primeras y los segundos, temática que, liderada por expertos en diálogo comunitario, exigió el diseño y puesta en marcha de una metodología especial de participación y consulta frente a cada avance en la nominación. Este proceder cosechó frutos que tomaron forma como acuerdos-compromiso firmados por los dirigentes de las comunidades o representantes de los vecinos para la protección y gestión del Qhapaq Ñan. No obstante este esfuerzo, y tras un largo proceso informativo y de consulta, al menos dos comunidades manifestaron claras negativas a permitir que los bienes culturales del Qhapaq Ñan que estaban en sus territorios ancestrales se incorporaran en la nominación, razón por la cual tuvo que ajustarse la selección territorial. En la actualidad, una de estas comunidades ha reconsiderado su posición inicial y ha solicitado agregarse a aquélla en una posible segunda etapa o extensión futura del Qhapaq Ñan en Chile.

\section{Condicionantes nacionales para la conservación del Qhapaq Nan en Chile}

El marco legal que establece la protección a los bienes culturales en Chile se regula a través de la Ley 17.288 de Monumentos Nacionales de 1970 (MECH 1970). Previo a esta normativa, oficiaba el CMN, creado en 1925 por el Decreto Ley núm. 651, que operaba de forma restringida en cuanto a sus ámbitos de acción: los monumentos históricos y públicos, las excavaciones arqueológicas y el registro e inscripción de museos, y el número de integrantes o consejeros (MECH 1925). En este periodo el accionar de la institución fue bastante irregular. Se declararon 50 monumentos históricos, que en su gran mayoría correspondieron a iglesias, fuertes y edificios públicos.

La citada Ley 17.288 define un marco conceptual y categorización patrimonial, si bien más amplio, hoy en día 
muy cuestionado: el contenido aborda la definición de las categorías de "monumentos", específicamente en lo que se refiere al patrimonio construido y los lugares naturales con valores culturales excepcionales (MECH 1970).

Institucionalmente, y en cumplimiento con lo que dicha ley dispone, en 1970 se reinstaló el CMN, que integraron veinte consejeros y ocho asesores - representantes de diversos servicios de gobierno y de la sociedad civil, esto es, de instituciones públicas y privadas (específicamente, gremios de escritores, historiadores, arquitectos) como un órgano colegiado en la materia que designaría un secretario ejecutivo, cuya responsabilidad consistiría en elaborar las actas de las sesiones del Consejo, que se realizarían una vez al mes (Ministerio de Educación 1970). Con el pasar de los años esta Secretaría Ejecutiva, que inicialmente residía en una sola persona, empezó a crecer de acuerdo con el nivel de obligaciones que iba demandando el tema patrimonial. Actualmente el CMN cuenta con un poco menos de 100 personas y con cierta representación regional, aunque la ley no prevé una regionalización efectiva.

Estatutariamente, el CMN es un órgano descentralizado del Ministerio de Educación que no posee la condición de servicio público y sólo recibe presupuesto para su funcionamiento mínimo, sin asignación extrapresupuestaria para llevar a cabo tareas propias de una institución de esta naturaleza, como el registro, la conservación, la puesta en valor. Así, en la actualidad se enfoca primordialmente en los aspectos normativos que prescribe la ley, por lo que se ha transformado en una entidad de evaluación a cuya consideración se someten, para su autorización o rechazo, los proyectos arquitectónicos, energéticos, ambientales, de investigación que pudieran afectar algún monumento nacional o su entorno próximo. Dados sus recursos y las demandas de su papel normativo, existe una incipiente capacidad al interior del organismo para elaborar proyectos propios, y en el último año se han efectuado importantes esfuerzos para producir un sistema de geodatos sobre los monumentos nacionales.

Es este consejo la institución que estimará el valor de los bienes culturales para su declaratoria —en las categorías de histórico, zona típica, santuario de la naturalezacomo monumento, la cual si bien determina medidas de protección y salvaguardia, no es aplicable a los bienes arqueológicos, ya que se establece su definición como monumentos por el simple ministerio de ley, condición que, aunque teóricamente tiende a favorecer el reconocimiento patrimonial, en la práctica no proporciona garantías ciertas para su protección.

En tal contexto nacional, quizá bastante más favorable que siete años antes, en 2003 transfirió el mandato de la Cancillería al CMN para que este último se hiciese cargo del desarrollo de la nominación del Qhapaq Ñan. En ese entonces la jefatura del CMN instruyó la creación de una unidad especial que llevara a cabo las actividades y procesos requeridos para la nominación y se encargara de ello como un proyecto de escala nacional. De esta manera, después de intentar que los estudios necesarios se efectuaran internamente y de no poder alcanzar los estándares necesarios para una iniciativa de esta naturaleza, esta unidad se ha enfocado en gestionar recursos externos, para lo que ha presentado proyectos a través del sistema de inversión pública.

Por medio de este sistema se ha logrado la aprobación de los proyectos; se ha generado el enlace interinstitucional y, al alero del Programa BID-SUBDERE-DAMOP,9 "Puesta en Valor del Patrimonio", se ha obtenido financiamiento, logrando concretar los medios que demanda esta iniciativa internacional; a la fecha se han aprobado 15 estudios y proyectos, sumados a la adquisición de asistencia técnica (contratación de profesionales e instalación de oficina en la localidad de San Pedro de Atacama) por un monto total de 3172000 dólares, de los cuales 925000 dólares corresponden al presupuesto del propio CMN. Es gracias a estos recursos como se han logrado importantes avances, a seguir:

- El cumplimiento con los contenidos del expediente de nominación internacional, de acuerdo con el estándar técnico generado entre los seis países socios de la iniciativa y con las exigencias definidas en las Directrices Operativas (UNESCO 2012). Como parte de ello, se ha desarrollado un conjunto de líneas bases (territoriales, ambientales y socioculturales), diagnósticos (de conservación para la puesta en valor) y registros que han permitido completar los antecedentes técnicos que demanda la construcción del expediente de nominación, tales como: levantamientos y registros arqueológicos, obtención de imágenes satelitales, planos topográficos y arquitectónicos de los bienes por nominar. También se han definido las bases metodológicas para generar los modelos de gestión y los planes de manejo pertinentes para cada tramo seleccionado.

- La devolución y traspaso a las comunidades asociadas de los resultados obtenidos en los estudios, con lo que se han abierto oportunidades para que la información sea de utilidad en la documentación y apoyo para la gestión de proyectos por parte de cada comunidad, otorgándoles herramientas para la consecución de objetivos para mejorar la calidad de vida de quienes la habitan.

- La creación de los insumos necesarios para la puesta en valor sostenible de los bienes culturales de las comunidades asociadas, de acuerdo con la noción de nuestros pueblos: se ha incorporado aquella, ya referida, del "buen vivir" o sumak kawsay (en aymara, como se ha dicho), suma qamaña (en quechua) de los bienes del Qhapaq Ñan, señalando que el esquema adoptado

\footnotetext{
${ }^{9}$ Programa del Banco Interamericano de Desarrollo, en conjunto con la Subsecretaría de Desarrollo Regional y la Dirección de Arquitectura del Ministerio de Obras Públicas.
} 
para la sostenibilidad de esta postulación se ha trabajado directamente con las regiones, municipios y comunidades para que, una vez declarado Sitio de Patrimonio Mundial, éstos no sean meros espectadores, sino los protagonistas de sus resultados.

- La mencionada apertura, como un hito trascendental en el posicionamiento a escala nacional y regional, de una sede regional del CMN y del Qhapaq Ñan en la localidad de San Pedro de Atacama, a través de la cual, y de su personal, se ha supervisado el trabajo en terreno de las consultoras que ejecutan los proyectos, y se ha desarrollado una vinculación más directa y cercana con las comunidades asociadas.

Todos éstos son avances considerables que, con los resultados obtenidos, han conllevado a la elaboración del expediente de nominación y al desarrollo de estrategias que, como hemos mencionado, ya se han conjugado con el esfuerzo de las otras naciones involucradas para la presentación de la iniciativa ante las autoridades encargadas del proceso de inscripción en la Lista del Patrimonio Mundial.

Naturalmente, estos logros también han conducido a una serie de reflexiones respecto de los desafíos nacionales para la conservación del Qhapaq Ñan en Chile, misma que se sintetiza en el siguiente apartado a manera de conclusiones.

\section{Conclusiones: desafíos nacionales para la conservación del Qhapaq Ñan en Chile}

Es posible distinguir diferentes ámbitos de desafíos para la conservación presente y futura del Qhapaq Ñan, a seguir:

Ámbito institucional, legal y normativo

Un factor que seguirá incidiendo en la conservación del Qhapaq Ñan es la naturaleza política de la iniciativa de su nominación a la Lista del Patrimonio Mundial, la cual ciertamente repercute de manera positiva en aspectos multilaterales y bilaterales de la relación con los países socios, lo que se refleja en el Comité de Gestión Internacional, donde nuestra cancillería y sus representantes para el proyecto tienen un papel preponderante. No obstante, esta condición política, que periódicamente también incide en los cambios de gobierno, afecta de manera directa la mirada y prioridad que se le da al tema, lo que provoca vaivenes en el desarrollo de las etapas necesarias para la puesta en valor del bien patrimonial.

Comparativamente, en el caso peruano la iniciativa de nominación del Qhapaq Ñan ha fortalecido la condición de proyecto país, a través del dictado de los Decretos Supremos 032-2001-ED y 035-2001-ED (MCP 2001a y 2001b) que aseguran la protección y el financiamiento permanentes para la ejecución del Proyecto Nacional
Qhapaq Ñan, incorporando lo nominado y gran parte de la red existente en el Perú. ${ }^{10}$

Aunque, con base en el antecedente peruano, Chile ya ha presentado un proyecto de ley para la dotación de recursos anuales a los sitios de Patrimonio Mundial ya inscritos, en los que aún no se encuentra el Qhapaq Ñan, persiste incertidumbre sobre su aprobación (Figura 6).

Otro aspecto ligado a la situación institucional y normativa chilena es la condición privilegiada de las figuras de protección a territorios dedicados a la minería y al desarrollo de proyectos energéticos. Para el caso del Qhapaq Ñan, dada la longitud en su recorrido y los paisajes que atraviesa, así como la riqueza mineral de los mismos, las ventajas de que gozan los proyectos ligados a la explotación y generación de estos recursos se constituye como el factor contextual determinante para la posibilidad de conservar íntegramente el bien cultural y el significado que la cosmovisión andina le otorga al territorio que, como un todo, éste ocupa. Una paradoja es que, coincidentemente, lo que el Inca buscaba en el pasado en los territorios chilenos hoy en día también es materia de interés de las grandes compañías mineras y energéticas. Esta amenaza permanente sobre el paisaje resulta uno de los desafíos más complejos en el manejo patrimonial de Chile. Si bien la iniciativa del Qhapaq Ñan intersecta las funciones el Sistema de Evaluación Ambiental, éste se ve constantemente sometido a las presiones políticas y empresariales. Por ahora, hemos logrado solventar con relativo éxito las afectaciones que este tipo de desarrollo pudiera traer en el Qhapaq Ñan, pero nada asegura que persista esta condición (Figura 7).

Dentro de las acciones legales que aún quedan por instrumentar en el marco del Proyecto Qhapaq Ñan en Chile, al CMN le queda declarar, bajo la figura jurídica de protección nacional de monumento histórico, las zonas de amortiguamiento, o área buffer, de los caminos y sitios arqueológicos que serán nominados a la Lista del Patrimonio Mundial. Esto significa que, aunque estas zonas se presentaron internacionalmente como parte del área de protección del sitio de patrimonio cultural de la humanidad, es necesario conformar, a partir de una declaratoria de monumento nacional, un expediente para obtener protección en el ámbito nacional. Cabe subrayar que un factor a favor en la protección técnica del propio sistema vial andino procede de una buena práctica en materia de

\footnotetext{
${ }^{10}$ Gracias a estos decretos (MCP 2001ª 2001b), el financiamiento para la ejecución del Proyecto Qhapaq Ñan (nacional) en el Perú proviene de los ingresos que se captan por la visita a la Red de Caminos Inka, esto es, recursos provenientes directamente del Tesoro Público. Así, la recaudación total se destina a dos ámbitos territoriales peruanos: Sede Nacional y Sede Cusco, cuya administración corresponde a la sede nacional del Ministerio de Cultura y a la Dirección Regional de Cultura Cusco; aquélla se ha destinado, entre los años 2006 y 2012, para el proceso de nominación y los proyectos de conservación ligados a la postulación del Qhapaq Ñan-sistema vial andino a la Lista del Patrimonio Mundial.
} 


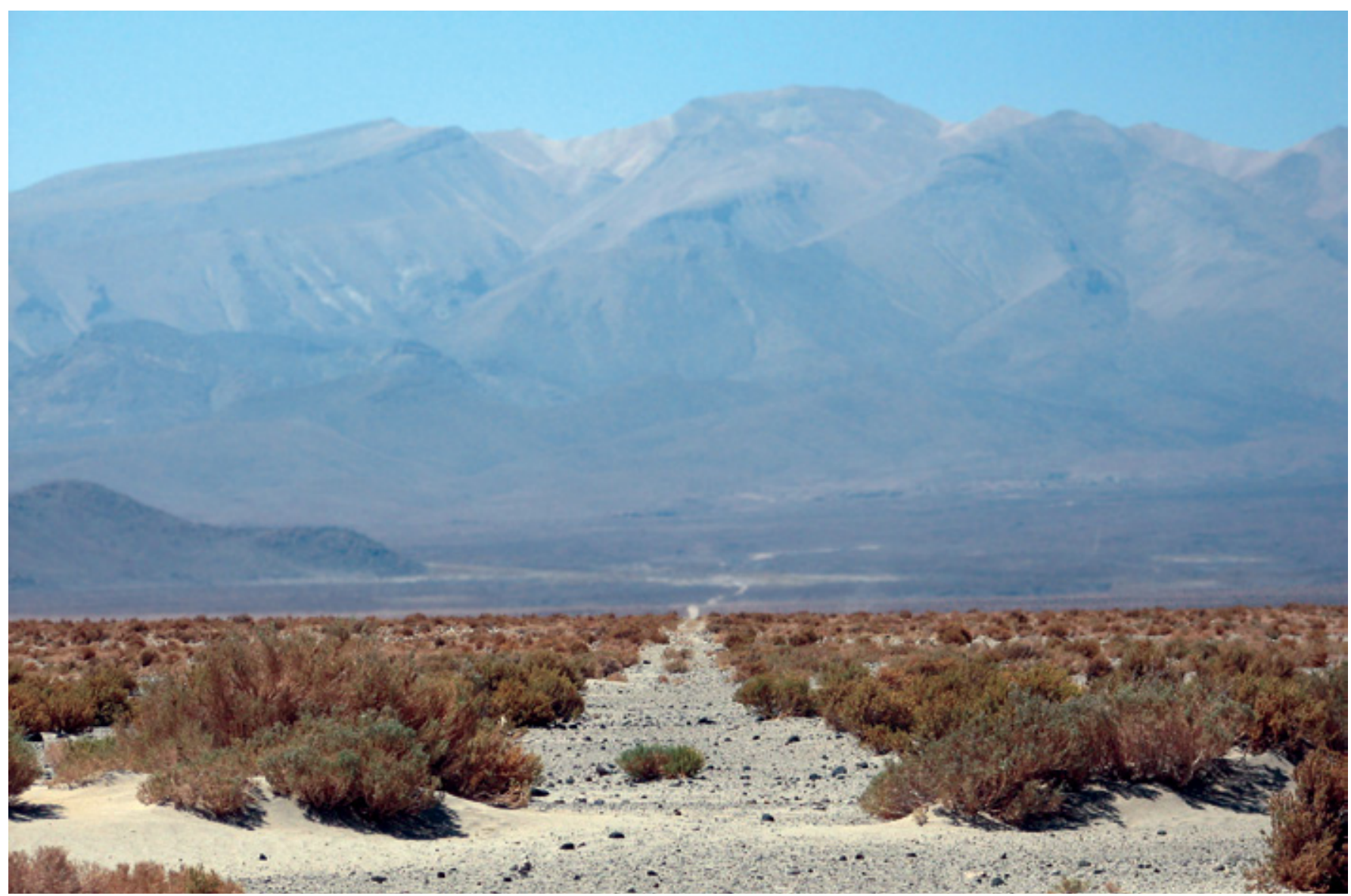

FIGURA 6. Sección Turi Norte: el desarrollo del Qhapaq Nan en el desierto próximo a Atacama, Chile (Cortesía: CMN, Chile, 2011).

delimitación, que se produjo durante el proceso de gestión rumbo a la nominación: se trata de la "zonificación participativa", una fórmula dinámica de protección derivada de la alianza y acción de las comunidades asociadas a sectores del Qhapaq Ñan, cuyo proceso de desarrollo consistió en dos fases: una técnica, articulada con base en los criterios y las recomendaciones emanadas de los estudios territoriales, ambientales y de conservación, y otra, más social, como consecuencia de la consulta a las comunidades indígenas y locales asociadas al Qhapaq Ñan. Esta última fase permitió definir, de manera consensuada con los futuros gestores del bien cultural, zonas de protección. Adicionalmente, gracias a este esquema de consulta y de participación comunitaria, al interior del CMN se ha creado sobre la gestión activa del Sistema Vial Andino una dimensión de conocimiento y de hacer que no tiene precedentes ni parangón.

\section{Conservación efectiva}

Previamente al inicio del proceso de nominación del Qhapaq Ñan a la Lista del Patrimonio Mundial, en el año 2001, sólo en el Perú se llevaban a efecto medidas de conservación periódicas y de carácter institucional en los caminos incaicos, concretamente, en aquellos cerca- nos al Santuario de Machu Picchu, las cuales era posible distinguir de las acciones de mantenimiento propias del esquema comunitario. En esas fechas, en la mayoría de los países que hoy ocupan el antiguo imperio del Tawantinsuyu, arqueólogos, antropólogos y otros profesionales habían estudiado en diferente grado de detalle los caminos asociados a la presencia Inca; sin embargo, dicho patrimonio no era objeto de un tratamiento periódico ni de la atención institucional requerida en función de su relevancia cultural.

Hoy en día, la mayor parte de los caminos del Sistema Vial Andino continúa en uso por parte de las comunidades cercanas, principalmente, como arterias de transporte humano o ganado (Figura 8). En el caso chileno destacan dos situaciones diferenciales. La primera, determinada por las condiciones inhóspitas del trazado en el cruce del Desierto de Atacama, hace que existan escasas comunidades en el entorno inmediato al Qhapaq Ñan, lo cual limita su mantenimiento tradicional. En segundo término, se ha producido segmentación del sistema vial a lo largo del camino y en relación con las comunidades cercanas, lo que ha significado la discontinuidad de algunas de las prácticas ancestrales que se realizaban en él. Ello se ve agravado por la llegada de nuevos caminos — las carreteras-y la incorporación de nuevas formas de transporte 


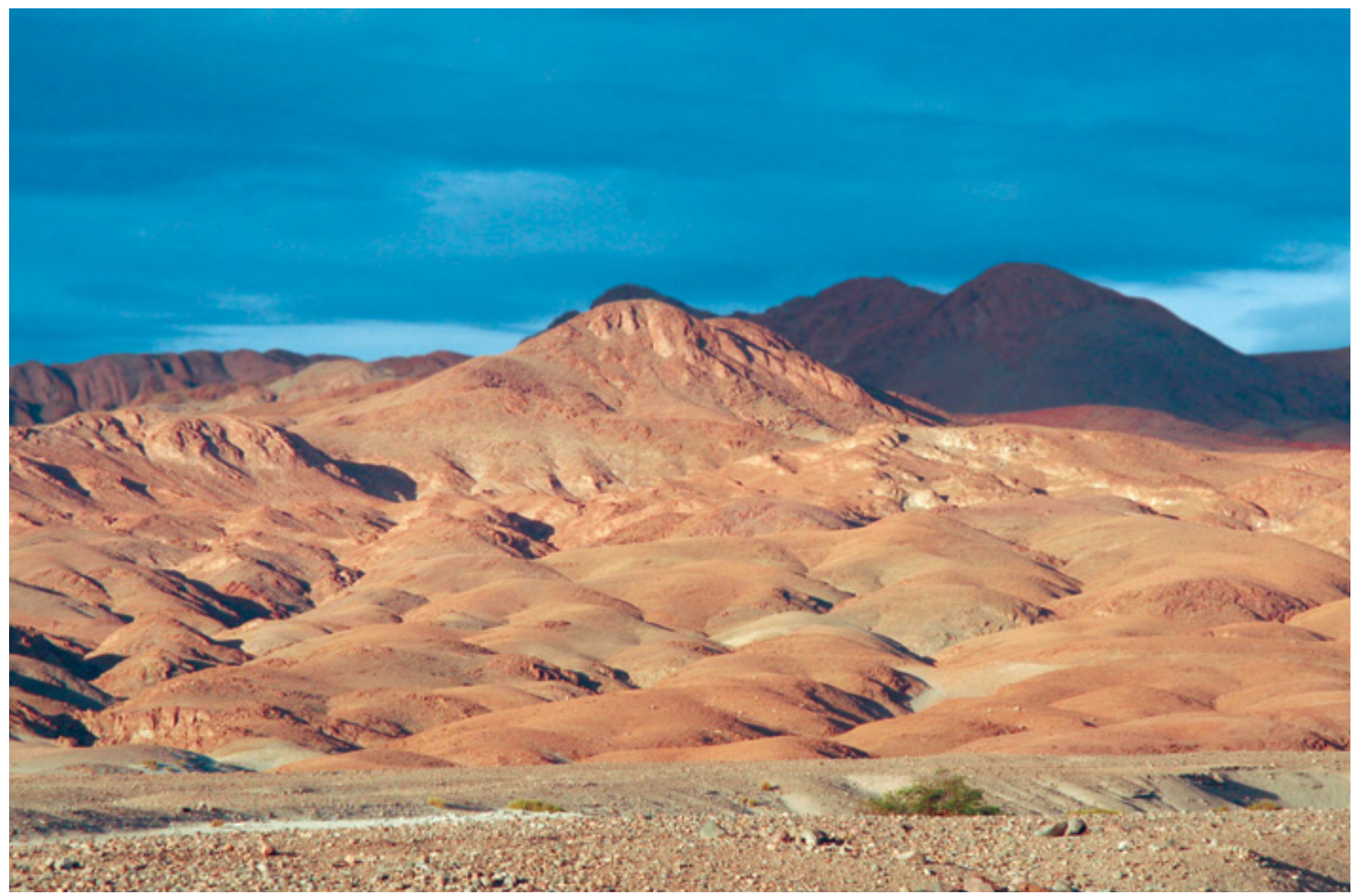

FIGURA 7. Atardecer en la Cordillera de los Andes, Subtramo Camar-Peine, Sistema Vial Andino, Chile (Cortesía: CMN, Chile, 2011).

—el automóvil—. En estos últimos segmentos, las comunidades han dejado de realizar trabajos comunitarios, como la "limpia de canales" de riego para el cultivo en terrazas y el mantenimiento de caminos, que incluía limpieza, quema de arbustos y hierbas, reforzamiento de drenes, despeje de material, reconstitución de muros y empedrados, y, por lo tanto, se ha propiciado un ciclo de alteración progresivo inversamente proporcional al abandono de la función activa del Sistema Vial Andino, cuyos efectos son difícilmente manejables.

En efecto, la riqueza tipológica del Qhapaq Ñan, la variedad de sitios arqueológicos asociados y la condición de bien lineal, en su paso por una gran diversidad de ambientes de vida, ha dificultado que se cree una metodología internacional para el diagnóstico del estado de conservación y, por consiguiente, que se definan las acciones e intervenciones necesarias en cada caso. Hay que considerar que para efectuar un levantamiento pormenorizado de alteraciones se requiere información cartográfica y topográfica expresada en escalas bajas (1:20, 1:50, 1:1000, $1: 200,1: 500$ ) tanto para caminos como para sitios, lo que eleva el costo de los insumos previos para cada uno los países $y$, en consecuencia, imposibilita que todos cuenten con información tan minuciosa, considerando a su vez las magnitudes del itinerario que cada país está no- minando. En nuestro caso, el chileno, no obstante que se ha logrado recabar insumos territoriales que permitían un diagnóstico en detalle, la dificultad radicó en la complejidad administrativa para la contratación de terceros y en la ausencia de equipos nacionales capacitados en conservación de bienes inmuebles arqueológicos, lo que llevó a solicitar a la consultora encargada que contratara experimentados profesionales extranjeros - conservadores y restauradores mexicanos- De esta forma, a pesar de que se logró incorporar liderazgo en los equipos nacionales - a los que se capacitó en terreno- mediante la generación de las metodologías necesarias para realizar el diagnóstico, cuyos resultados son notables, lamentablemente no ha habido decisión y voluntad para proseguir con este esquema de cooperación internacional hacia las etapas de ejecución (Figura 9).

La tarea de conservar el Qhapaq Ñan en un país con una austeridad institucional y presupuestaria en materia patrimonial, a la que se suma la falta de profesionales capacitados y especializados en restauración de inmuebles arqueológicos, hace que el comienzo del verdadero trabajo frente a un sitio del Patrimonio Mundial se convierta en un tremendo reto. En esta situación, la oportunidad de realizarlo desafía los paradigmas de la conservación tradicional, por lo que la apuesta radica en generar una 


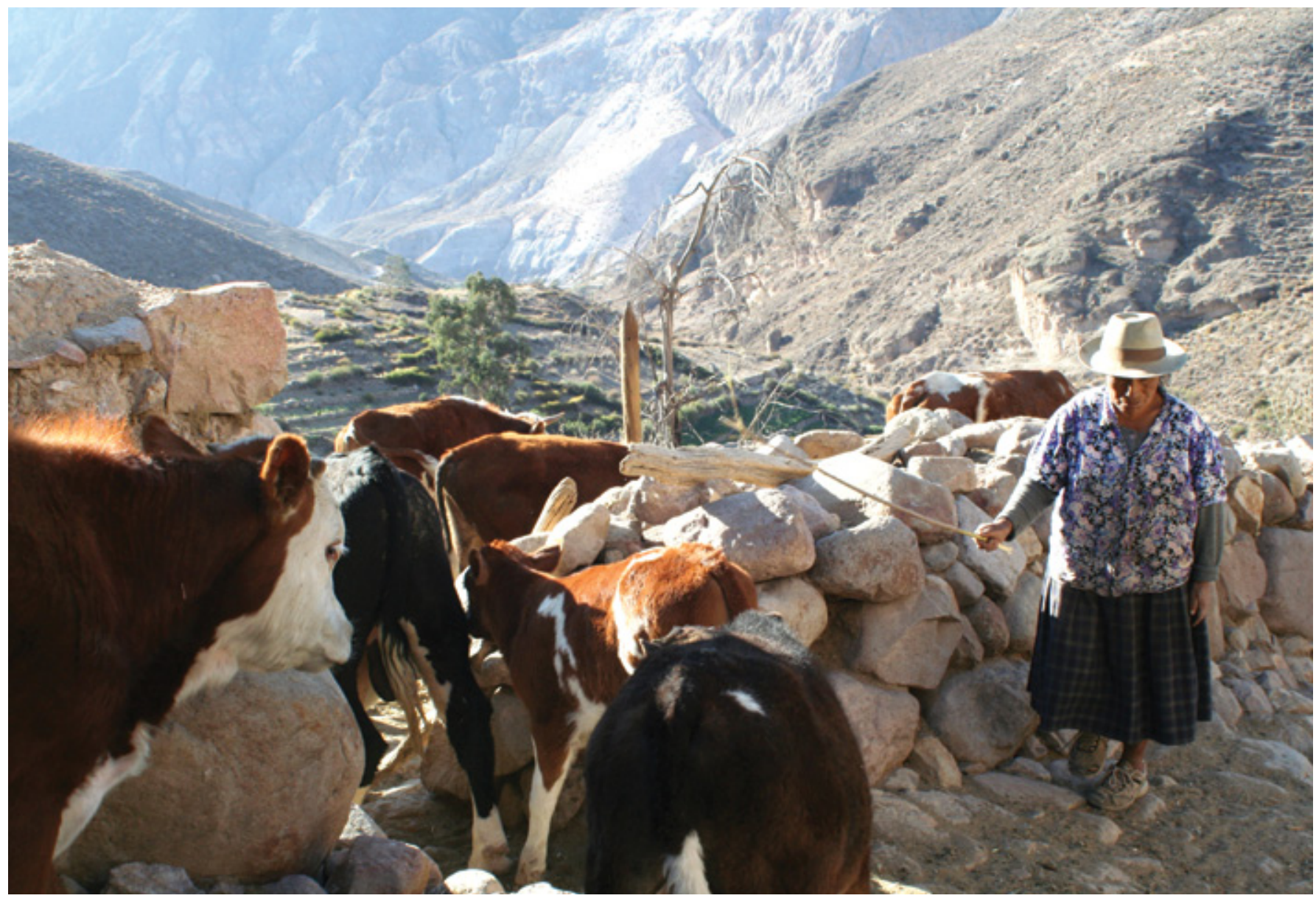

FIGURA 8. Pastora en cercanías de Socoroma: la persistencia del uso del Sistema Vial Andino en la actualidad de Chile (Cortesía: CMN, Chile, 2011).

gestión colaborativa como mecanismo que podría asegurar la protección y conservación del bien, empoderando a las comunidades, a los actores territoriales y a las instituciones locales como los gestores del patrimonio: con capacitación y acompañamiento, ellos podrían llevar a cabo esta tarea.

Un aspecto digno de consideración es que la capacitación de comunidades y actores locales se está desarrollando a partir de su propia petición y con base en un plan de educación que busca lograr transferir competencias, habilidades y conocimientos a líderes comunitarios y actores involucrados. Hoy en día, el propósito es facilitar los procesos de articulación e integración de/hacia los modelos de gestión para el manejo de los bienes culturales nominados, y para ello ya se cuenta, a modo de insumo, con los resultados para el diseño e implantación de componentes educativos del plan maestro y de los planes de manejo.

El proyecto ad portas de iniciar es la ejecución del plan maestro como instrumento de planeación y ordenamiento para una adecuada conducción de cada segmento nominado. En el desarrollo de los planes de manejo a través de metodologías de participación y de consulta a los actores territoriales se irá construyendo una gestión compartida, instrumento que ayudará a planificar las acciones necesarias para la protección y conservación del bien, así como las medidas para el desarrollo local y apropiado, la capacitación y formación, el fortalecimiento de la identidad local, la difusión y comunicación, el uso público, el registro y catalogación, entre otros componentes. En el transcurso de su elaboración, se instalarán jurídicamente los comités de Gestión de Tramo y las unidades de Gestión Local, que serán los entes responsables de la habilitación de los planes de manejo (Figura 10).

Ahora bien, es obvio que en estos esfuerzos se requerirán grandes dosis de cooperación internacional, para formar generaciones de especialistas en conservaciónrestauración arqueológica y contar con asistencia técnica en terreno. Éste es, sin duda, uno de los factores desfavorables a la hora de pensar en las intervenciones prioritarias que se necesitan tanto para los caminos como para los sitios arqueológicos del Qhapaq Ñan, pensando en la posibilidad de que éstos puedan ser interpretados para su visita y gestionados por los actores locales.

Sólo con una gestión activa y participativa del proyecto nacional se abrirán oportunidades para la conser- 


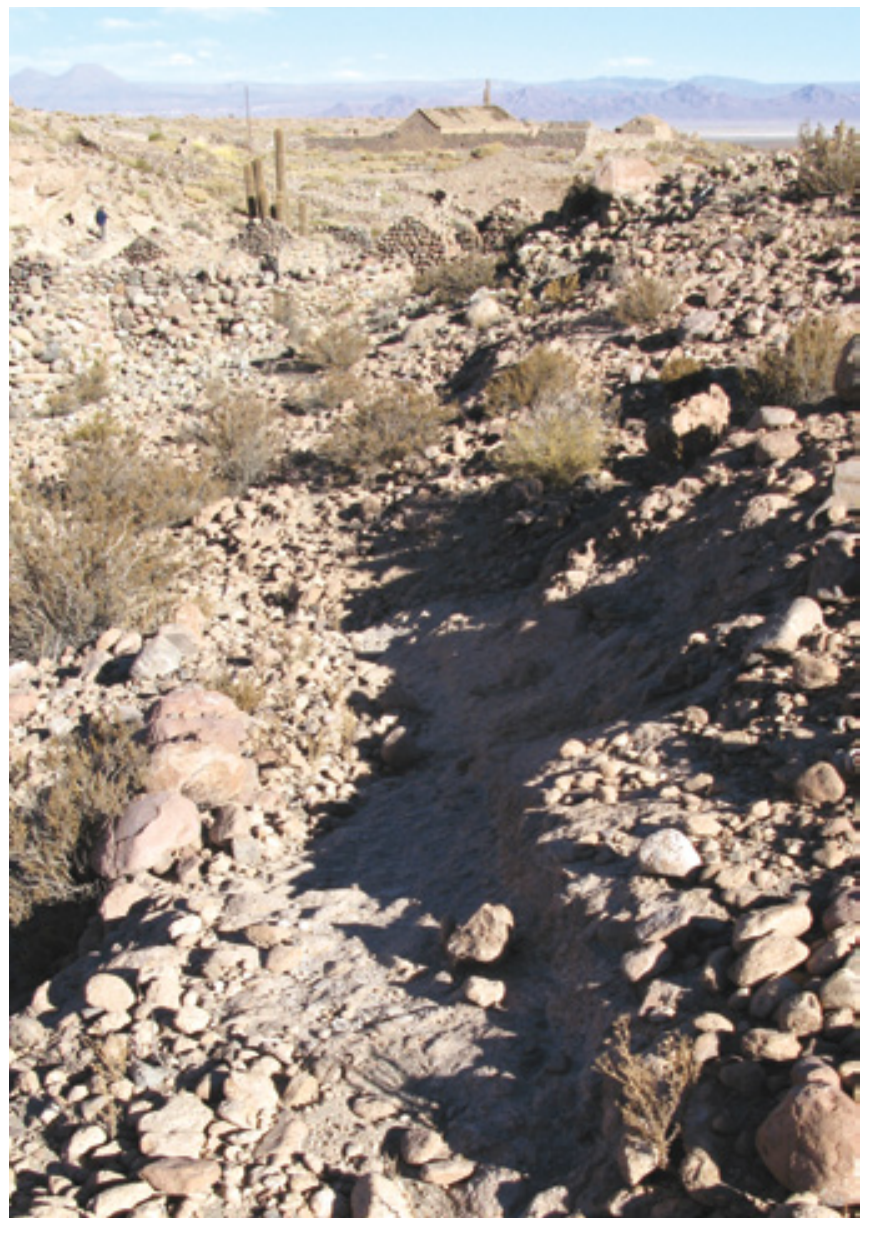

FIGURA 9. Camino que se dirige al Pueblo Viejo de Cupo (Cortesía: CMN, Chile, 2009).

vación de los valores de este patrimonio cultural andino y para el "buen vivir" que tanto anhelan sus comunidades.

\section{Referencias}

Ámbito Consultores Ltda.

2012 Diagnóstico de situación del Qhapaq Ñan en Chile, componente de Estado de conservación, documento mecanoescrito, Santiago de Chile, Ministerio del Interior/Subdere/ Ministerio de Educación/CMN/Unidad Técnica Qhapaq Ñan.

Caraballo Perichi, Ciro y Nuria Sanz (coords.)

2004 Tejiendo los lazos de un legado. Qhapaq Nan-Camino Principal Andino: hacia la nominación de un patrimonio común, rico y diverso, de valor universal, Lima, UNESCO-Perú.

ENQN

2013 “Expediente de Nominación del Qhapaq Ñan a la Lista del Patrimonio Mundial", documento mecanoescrito, Santiago de Chile, Archivo del CMN.

Hyslop, John

1984 The Inka Road System, Nueva York, Academic Press. 1992 Qhapaq Nan. El sistema vial incaico, Lima, Instituto Andino de Estudios Arqueológicos/Instituto Geológico Minero y Metalúrgico del Perú.

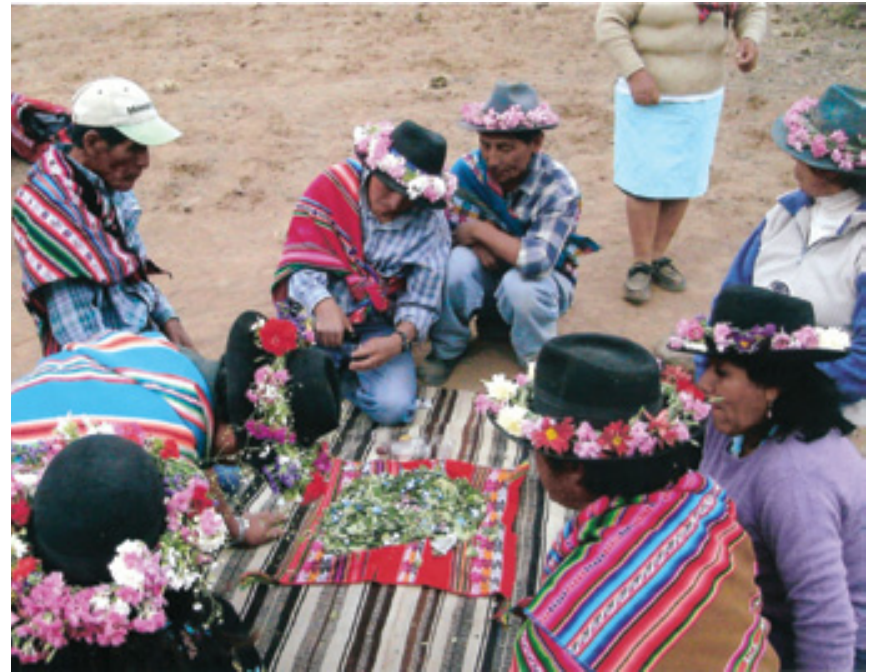

FIGURA 10. Pachallampe. Fiesta del Pachallampe, o de la cosecha de la papa, asociada a la funcionalidad del Sistema Vial Andino (Cortesía: CMN, Chile, 2011).

ICOMOS

1990 Carta Internacional para la Gestión del Patrimonio Arqueológico, Londres, ICOMOS.

1994 Documento de Nara sobre la autenticidad, Nara, UNESCO/Gobierno de Japón/ICCROM/ICOMOS, documento electrónico disponible en [http://www.esicomos.org/Nueva carpeta/info_DOC_NARAesp.htm], consultado en agosto de 2012.

1999 Carta del Australia-ICOMOs para la Conservación de Lugares de Significación Cultural (Carta de Burra), documento electrónico disponible en [www.icomos.org/charters/burra1999_spa.pdf], consultado en agosto de 2012.

Infracon

2010 "Estudio diagnóstico del estado de situación del Qhapaq Ñan en Chile, Componente de Registros", documento mecanoescrito, Santiago de Chile, Ministerio del Interior/Subdere/Ministerio de Educación/CMN/Unidad Técnica Qhapaq Nan.

MCP

2001a Decreto Supremo 032-2001-ED, Ministerio de Cultura, Gobierno del Perú, Diario Oficial el Peruano, Lima, Editora Perú.

2001b Decreto Supremo 035-2001-ED, Ministerio de Cultura, Gobierno del Perú, Diario Oficial el Peruano, Lima, Editora Perú. $\mathrm{MECH}$

1970 Ley 17.288 de Monumentos Nacionales, Santiago de Chile, Ministerio de Educación, Gobierno de Chile.

1925 Decreto Ley núm. 651, Ministerio de Educación, Santiago de Chile, Gobierno de Chile.

OrionData

2010 "Levantamientos terrestres para los tramos del itinerario y paisaje cultural del Qhapaq Ñan-Chile, relevamientos arquitectónicos de sitios arqueológicos en la región de Antofagasta", documento mecanoescrito, Santiago de Chile, OrionData. 
UNESCO

2012 Directrices Operativas de la Convención de Patrimonio Mundial, Cultural y Natural, París, UNESCO/Intergovernmental Committee for the Protection of the World Cultural and Natural Heritage, World Heritage Committee.

Universidad de Chile/Departamento de Antropología

2009 “Estudio diagnóstico de situación del Qhapaq Nan en

Chile; componente Difusión e investigación para las regiones

\section{Resumen}

El presente informe examina el proceso de nominación del Qhapaq Ñan, o Sistema Vial Andino, a la Lista del Patrimonio Mundial de la UNESCO; lo hace, por un lado, desde un marco histórico general y, por el otro, a partir de la especificidad de las estrategias y acciones realizadas por el Consejo de Monumentos Nacionales de Chile. Aunado al análisis de los logros alcanzados durante un trayectoria de trabajo de más de 10 años, se señalan las limitaciones y desafíos encontrados, ello con la finalidad de reflexionar sobre los retos que implican la gestión participativa para la conservación y el manejo de una de las obras patrimoniales excepcionales de la humanidad.

\section{Palabras claves}

Sistema Vial Andino (Qhapaq Ñan); conservación; gestión; nominación; Lista del Patrimonio Mundial de Arica-Parinacota y Atacama", documento mecanoescrito, Santiago de Chile, Universidad de Chile.

Urbe, S. A.

2010 "Diagnóstico del estado de situación del Qhapaq Ñan en Chile, componente Ambiental-Territorial, Informe final", documento mecanoescrito, Santiago de Chile, Ministerio del Interior/Subdere/Ministerio de Educación, CMN/Unidad Técnica Qhapaq Ñan.

\section{Abstract}

This report examines the nomination process of the Qhapaq Nan or Andean road system to UNESCO's World Heritage List, by analyzing, on the one hand, its general historical development, and on the other hand, the specific strategies and actions undertaken by the Consejo de Monumentos Nacionales (National Council for Monuments), Chile. Examining the achievements attained throughout a working period of more than 10 years, this contribution focuses on the limitations and challenges that the project has faced in order to point out the issues at stake within the participatory planning process for the conservation and management of one of the most outstanding examples of human heritage.

\section{Key words}

Andean Road System (Qhapaq Nan); conservation; management; nomination; World Heritage List

Título en inglés: Qhapaq Ñan, Andean Road System: The Challenge of its Conservation in Chile during its Nomination to the World Heritage List 